\title{
Effects of a Rehabilitation Programme with a Nasal Inspiratory Restriction Device on Exercise Capacity and Quality of Life in COPD
}

\author{
Aurelio Arnedillo ${ }^{1} \oplus$, Jose L. Gonzalez-Montesinos ${ }^{2} \oplus$, Jorge R. Fernandez-Santos ${ }^{2,3}$, \\ Carmen Vaz-Pardal ${ }^{4}$, Carolina España-Domínguez ${ }^{1}$, Jesús G. Ponce-González ${ }^{3,5, * \mathbb{D}}$ and \\ Magdalena Cuenca-García 2,3 \\ 1 Pneumology, Allergy and Thoracic Surgery Department, University Hospital Puerta del Mar, \\ 11009 Cádiz, Spain; aurelioarnedillo@neumosur.net (A.A.); caroespana@hotmail.com (C.E.-D.) \\ 2 GALENO Research Group, Department of Physical Education, Faculty of Education Sciences, \\ University of Cádiz, 11003 Puerto Real, Spain; jgmontesinos@uca.es (J.L.G.-M.); \\ jorgedelrosario.fernandez@uca.es (J.R.F.-S.); magdalena.cuenca@uca.es (M.C.-G.) \\ 3 Biomedical Research and Innovation Institute of Cádiz (INiBICA) Research Unit, Puerta del Mar University \\ Hospital University of Cádiz, 11009 Cádiz, Spain \\ 4 Bahía Sur Andalusian Center for Sports Medicine, 11100 Cádiz, Spain; carmenvaz@hotmail.com \\ 5 MOVE-IT Research Group, Department of Physical Education, Faculty of Education Sciences, \\ University of Cádiz, 11003 Puerto Real, Spain \\ * Correspondence: jesusgustavo.ponce@uca.es
}

Received: 12 April 2020; Accepted: 20 May 2020; Published: 22 May 2020

check for updates

\begin{abstract}
Objective: The objective was to assess the effects of a nasal restriction device for inspiratory muscle training, called Feelbreathe ${ }^{\circledR}$, added to a rehabilitation program (RP) on exercise capacity, quality of life, dyspnea and inspiratory muscle strength in patients with stable COPD. Methods: Patients were randomized into three groups, one performed a supervised RP using the Feelbreathe ${ }^{\circledR}$ device (FB group), the second group developed the same RP with oronasal breathing without FB (ONB group) and the third was the control group (CG). We evaluated inspiratory muscle strength (PImax), dyspnea (mMRC), quality of life (CAT) and exercise capacity (6MWT) before and after 8-week of RP. Results: A total of 16 patients completed the study, seven in FB group, five in ONB group and four in the CG. After the RP, the FB group showed a significant increase in PImax ( $93.3 \pm 19.1$ vs. $123.0 \pm 15.8 \mathrm{mmHg})$ and in the $6 \mathrm{MWT}$ distance $(462.9 \pm 71.8 \mathrm{~m}$ vs. $529.1 \pm 50.1 \mathrm{~m})$ and a decrease in the CAT score $(9.7 \pm 6.5$ vs. $5.9 \pm 6.0)$ and in the mMRC dyspnea score. FB provides greater improvement in PImax, dyspnea, quality of life and 6MWT than ONB. Conclusions: The Feelbreathe ${ }^{\circledR}$ device provides greater improvements in quality of life, dyspnea, exercise capacity and inspiratory muscle strength compared to patients that did not use it.
\end{abstract}

Keywords: COPD; pulmonary rehabilitation; medical device; inspiratory muscle training

\section{Introduction}

The benefits of pulmonary rehabilitation programs (RP) in chronic obstructive pulmonary disease (COPD) patients have been shown and are recognized as an effective tool for improving dyspnea, exercise tolerance and quality of life in all the guidelines [1-4].

In addition to chronic airflow obstruction, COPD patients have frequent muscle dysfunction that is caused by the interaction of local and systemic factors that can involve respiratory and/or limb muscles $[5,6]$. Some authors explain that the limitation of COPD patients is not only in the respiratory muscles but also in the lack of skeletal muscle strength [7], which could justify carrying out respiratory 
muscle training and physical training jointly, so interventions that can improve the strength and endurance of the skeletal muscles, and in particular, of the inspiratory muscles, should be beneficial for these patients [8].

It remains unclear if the addition of inspiratory muscle training (IMT) to a general exercise training program leads to additional clinically relevant improvements in patients with COPD. In a review only in patients with inspiratory muscle weakness $\left(\mathrm{P}_{\text {Imax }}\right.$ less than $\left.60 \mathrm{~cm} \mathrm{H}_{2} \mathrm{O}\right)$, the addition of IMT to a general exercise training program improved $\mathrm{P}_{\operatorname{Imax}}$ and tended to improve exercise performance [9].

Current recommendations do not include IMT as an essential part of respiratory rehabilitation, however, IMT has been used as a complement added to the supervised pulmonary RP, and some studies have shown an improvement in inspiratory muscle strength, dyspnea and distance walked in the six minutes walking test (6MWT) after a IMT program in patients with COPD [10].

In a recent systematic review and meta-analysis, Beaumont et al. concluded that IMT using threshold devices improved inspiratory muscle strength, exercise capacity and quality of life. However, there was no added effect of IMT on dyspnea during pulmonary rehabilitation [11], but the devices used in these patients were in static position.

The methods most often used for IMT in COPD patients are resistive loading, pressure threshold loading and voluntary normocapnic hyperpnea. All these methods are currently used to improve inspiratory muscle strength [12], but have some limitations because the patients do not have physiologic respiration; must breathe by the mouth, not by the nose; and they must perform the training in static position but not in dynamic situations.

The Feelbreathe ${ }^{\circledR}$ device tested in our study can be used in static and dynamic situations [13] and is a nasal ventilatory flow restriction device made by a strip of hypoallergenic material (3M Spain, S.A. Medical Specialties/O.E.M.) that is placed and adhered under the nostrils (Figure 1), impairing the free pass of air through the nose by producing resistance to flow. Depending on the size or/and porosity of the device, the inspiratory process is more or less difficult. It can be used while performing dynamic exercise or doing daily living activities. The Feelbreathe ${ }^{\circledR}$ device (FB) has been authorized by the Spanish Agency for Medicines and Health Products for application on COPD patients (AEMPS-Madrid-Spain $\mathrm{N}^{\circ}$ : U201900103, N publication: ES1227865, 2017).
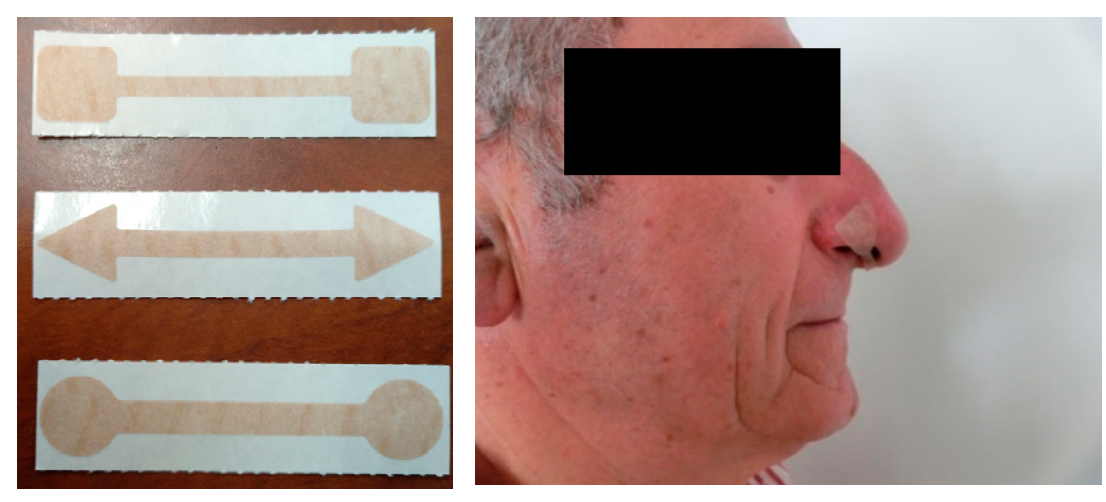

Figure 1. Three different sizes of the FeelBreathe ${ }^{\circledR}$ device: 4,5 and $6 \mathrm{~mm}$. FeelBreathe ${ }^{\circledR}$ device placed under the nostrils.

Previous studies have shown that an increased airflow resistance while breathing nasally, during exercise, increases the breathing effort [14] which may potentially improve the exercise tolerance [15] and energy efficiency [16]. In healthy subjects, FB has shown changes in lung ventilation, gas exchange and heart rate during exercise, with improvements in ventilatory efficiency [17]. 
Therefore, the objective of this study was to assess the effects of a nasal restriction device for inspiratory muscle training added to a supervised RP on exercise capacity, quality of life, dyspnea and inspiratory muscle strength in stable COPD patients. The hypothesis of this study was that the group who performed the training with the FB device could obtain higher benefits on exercise capacity, quality of life, dyspnea and inspiratory muscle strength.

\section{Materials and Methods}

\subsection{Study Population}

Subjects were recruited from the Pneumology outpatient of our University Hospital. Consecutive patients were screened by reviewing their charts and by interview. Inclusion criteria were diagnosis of COPD according to guidelines criteria $[1,18]$ with moderate or severe airflow obstruction (GOLD 2 or 3) [18], dyspnea grade 2 or greater by mMRC scale and a stable clinical condition for at least 2 months. Exclusion criteria were poor compliance, treatment with oxygen therapy or non-invasive mechanical ventilation, $\mathrm{CO}_{2}$ retention, medical conditions that can produce or increase dyspnea on exercise in addition to COPD (cardiovascular, metabolic or other respiratory diseases) or osteoarticular or neuromuscular diseases that may limit the correct performance of the 6MWT. Participants were randomly assigned according to a computer-generated randomization table to three groups: (1) those who participated in the supervised RP using the Feelbreathe ${ }^{\circledR}$ device (FB group), (2) those who participated in the supervised RP with oronasal breathing without the Feelbreathe ${ }^{\circledR}$ device (ONB group) and, (3) those included in the control group (CG), which received standard medical recommendations for patients with COPD.

Written informed consent was obtained from all patients before starting the study. This clinical trial received ethical approval from the Ethics Committee University Hospital Puerta del Mar and met the requirements of the Declaration of Helsinki. ClinicalTrials.gov Identifier: NCT03936348

\subsection{Study Protocol}

A total of 20 patients were included in this study (Figure 2). Demographic and clinical data were recorded. Dyspnea was assessed by the modified Medical Research Council (mMRC) dyspnea questionnaire [19] and quality of life by the COPD Assessment Test (CAT) questionnaire [20]. Spirometry was performed according to the American Thoracic Society (ATS) criteria [21,22] (Spirometer CPX, Cardinal Health, Hoechberg, Germany). Then, they performed a resting electrocardiogram (QRS Universal ECG, QRS, Plymouth, MN, USA). $P_{\text {Imax }}$ was measured during a maximal, static inspiratory effort measured at the mouth (Micro RPM, Micro Medical Ltd., Chatham, Kent, UK). $P_{\operatorname{Imax}}$ was recorded as the highest value averaged over $1 \mathrm{~s}$ from three maneuvers that varied by less than $10 \%$ and was measured based on three maximal reproducible respiratory efforts. Then, the patients performed the 6MWT according to the ATS guideline [23].

All tests were performed according to a standardized protocol before starting the training and 2 days after its completion. 


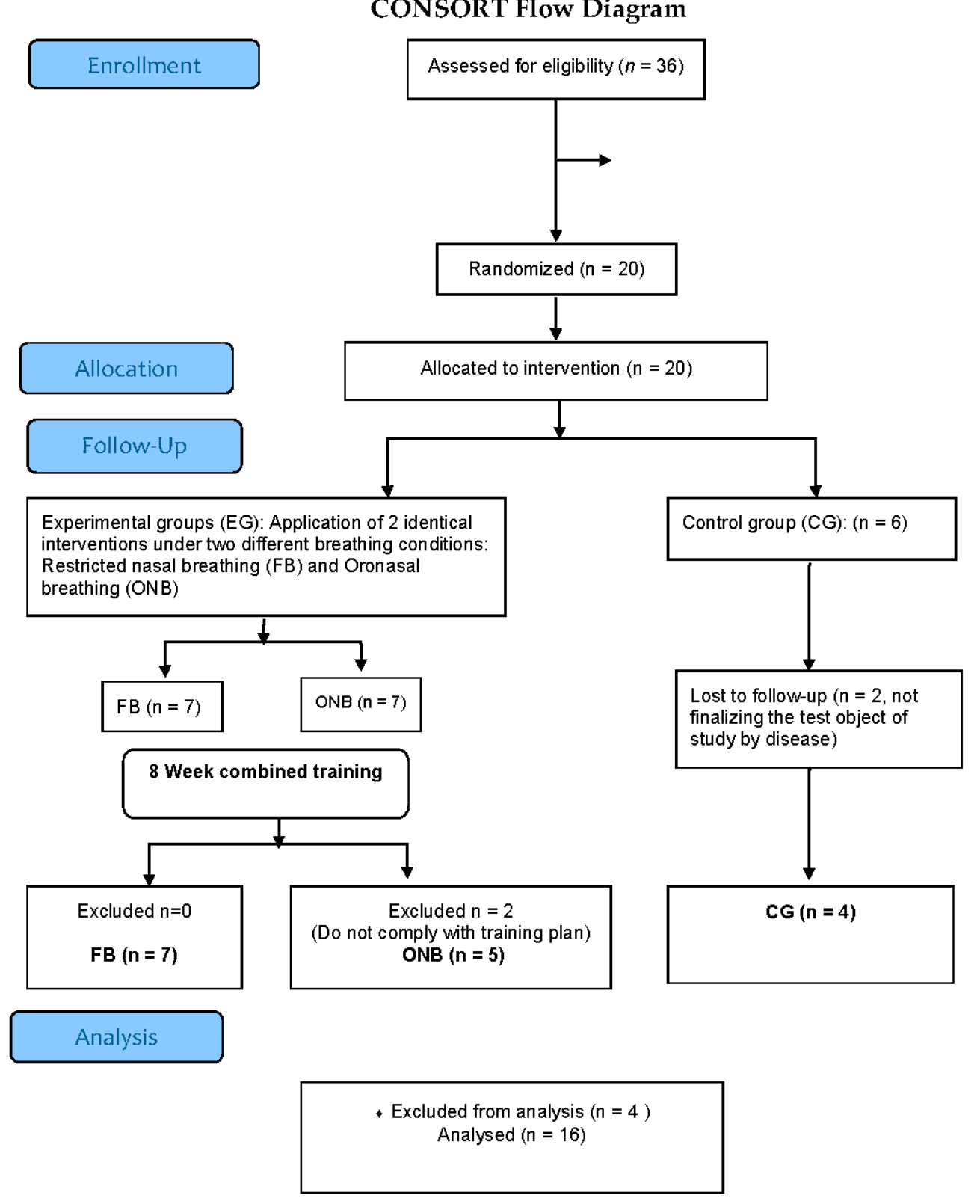

Figure 2. CONSORT Flow Diagram. Flow-chart showing inclusion, randomization and participation throughout the study.

\subsection{Training Program}

Participants carried out a supervised RP for 8 weeks, 3 days per week. The pulmonary RP included therapeutic education and training sessions lasting $60 \mathrm{~min}$ with a warming up phase, a main phase and a recovery phase. After each session, Borg's perceived exertion was measured [24]. The training program included aerobic exercise on cycle ergometers and on treadmills (progressing from 10' to 30' and from $40 \%$ to $75 \%$ of the reserve heart rate (RHR) or 6-7 score based on Borg's perceived exertion), strengthening of lower and upper limb muscle groups, breathing exercises (pursed lip breathing, diaphragmatic and abdominal breathing and diaphragmatic mobility) and finally, stretching exercises.

In the FB group, for restricted nasal breathing, at the beginning of the training program, the small size device was used $(4 \mathrm{~mm})$. The size of the device was progressively increased according to the patient adaptation to the 5 or $6 \mathrm{~mm}$ device, depending on the score on Borg's perceived exertion scale. If the patient had a score under 4 after the RP sessions, the size of the FB device was increased. 
FB was placed under the nostrils, using sterile gloves and assessing the patient did not have mucus or injuries. The device was used during the RP and patients were encouraged to do physiological breathing by nasal inspirations and mouth expirations.

\subsection{Statistical Analysis}

Descriptive data of the participants are expressed as mean \pm standard deviation or number and percentage for continuous and categorical variables, respectively. Percentage of change (\% $\mathrm{Change})$ for each variable was calculated as:

$$
{ }^{\%} \text { Change }=(\text { mean }(\text { Post-test value })-\text { mean }(\text { Pre-test value }) / \text { mean }(\text { Pre-test value })) * 100
$$

Differences among RP (between differences) and between pre- and post RP tests within each breathing condition (within differences) were analyzed using a Bayesian hierarchical model. 6MWT distance, $\mathrm{P}_{\text {Imax }}$ and CAT were considered as continuous variables, while mMRC dyspnea was treated as an ordinal variable. To analyze differences at baseline, only a categorical variable indicating the RP (CG, ONB or FB) was introduced in the model as predictor. However, to analyze both between and within differences RP, time (pre- or post-PR) and their interaction were introduced as predictor variables. Due to the sample size in our study, we choose to analyze our data using Bayesian inference, since it has proven to be a proper method of statistical inference for small sample size [25,26]. Weakly informative prior has been used on regression coefficients to address the issue of small sample size. This class of prior distribution encoded information to restrict the plausible range of values of a specific parameter but still leave a wide range of values to be covered [27]. Inference was performed based on the $95 \%$ credible interval (95\% CrI) which contains a range of values where we can be $95 \%$ certain that the true value lies, given the data at hand and the model fitted. The Bayesian hierarchical model was fitted using the package brms for the $\mathrm{R}$ programming language for statistical computing and graphics [28]. All parameters estimated showed a good convergence with values of $\hat{R}=1$ and number of effective sample size $>1000$. The code and the dataset to replicate the analysis are stored in https://github.com/JorgeDelro/COPD_2_1.

\section{Results}

Thirty-six patients were initially screened for the study from February to March 2017. Six patients declined to participate and ten had almost one exclusion criteria. Twenty subjects were initially randomized. Two patients assigned to ONB withdrew after finishing the RP without performing the final tests, one patient in the CG withdrew for the same reason and the other one due to a COPD exacerbation. Sixteen subjects completed the study (Figure 2).

There were no baseline differences between the groups, except in the forced vital capacity (FVC) that was worse in the ONB group compared to the CG $[-665,95 \%$ CrI $(-1317,-22.9)]$ (Table 1). No patient was underweight or had significant hyperinflation. No patient was on oral steroid therapy or showed clinical manifestation of muscle wasting.

The distance walked in the 6MWT increased in the groups that received PR (Figure 3). The increase was higher in the FB group than in the ONB group but both achieved the MCID defined as an increase equal or greater than $30 \mathrm{~m}$ [29].

Comparing changes in dyspnea, the probability of achieving a reduction in 1 point in the mMRC dyspnea scale, which is considered as MCID, was greater than 0.5 in the FB group and less than 0.5 in the ONB and CG (Figure 4). 
Table 1. Baseline characteristics of the patients.

\begin{tabular}{|c|c|c|c|c|c|c|}
\hline Variables & FB $(n=7)$ & ONB $(n=5)$ & CG $(n=4)$ & FB vs. ONB & FB vs. CG & ONB vs. CG \\
\hline Age (years) & $65 \pm 8.0$ & $72 \pm 7.4$ & $70.2 \pm 25.9$ & $-4.8(-14.8,6.2)$ & $-6.6(-15.5,3.6)$ & $1.7(-10.0,12.9)$ \\
\hline $\mathrm{BMI}\left(\mathrm{m} / \mathrm{kg}^{2}\right)$ & $28.4 \pm 4.2$ & $26.8 \pm 2.5$ & $25.9 \pm 2.1$ & $1.5(-2.4,5.4)$ & $2.3(-2.0,6.3)$ & $0.8(-3.6,5.5)$ \\
\hline DLCO $(\%)$ & $72.3 \pm 20.0$ & $71.4 \pm 8.8$ & $75.2 \pm 16.4$ & $0.85(-9.8,11.5)$ & $-2.95(-13.5,10.5)$ & $-3.8(-15.8,8.2)$ \\
\hline RV/TLC (\%) & $86.0 \pm 10.6$ & $84.5 \pm 12.0$ & $85.8 \pm 14.6$ & $1.5(-6.4,9.4)$ & $0.3(-7.6,8,1)$ & $1.3(-7.4,9.9)$ \\
\hline FEV (mL) & $1571 \pm 334$ & $1608 \pm 344$ & $1812 \pm 706$ & $-23.5(-557,469)$ & $-218(-760,349)$ & $194(-441,773)$ \\
\hline FEV $(\%)$ & $46.9 \pm 10.6$ & $51.2 \pm 9.8$ & $52.6 \pm 19.9$ & $-3.7(-18.4,11.1)$ & $-5.4(-21.6,10.8)$ & $-1.8(-19.8,16.1)$ \\
\hline FVC (mL) & $2869 \pm 298$ & $2580 \pm 577$ & $3270 \pm 474$ & $283(-260,801)$ & $-382(-929,207)$ & $-665(-1317,-22.9)^{\$}$ \\
\hline FVC (\%) & $63.9 \pm 8.3$ & $59.2 \pm 10.0$ & $67.1 \pm 13.8$ & $4.5(-7.4,17.1)$ & $-3.1(-15.9,10.1)$ & $-7.6(21.5,7.7)$ \\
\hline $\mathrm{FEV} / \mathrm{FVC}(\%)$ & $54.1 \pm 6.9$ & $62.6 \pm 5.6$ & $54.2 \pm 14.7$ & $-8.1(-18.7,2.8)$ & $0.0(-11.4,11.4)$ & $8.1(-4.2,20.8)$ \\
\hline $\mathrm{P}_{\text {Imax }}(\mathrm{mmHg})$ & $93.3 \pm 19.1$ & $85.6 \pm 23.9$ & $102 \pm 14.85$ & $7.9(-15.6,31.1)$ & $-7.6(-34.3,17.3)$ & $-15.5(-42.8,12.5)$ \\
\hline 6MWT (m) & $462.9 \pm 71.8$ & $439.1 \pm 81.4$ & $490.3 \pm 80.0$ & $23.6(-68.6,108.0)$ & $-25.8(-115.0,75.1)$ & $-49.4(-148.0,48.7)$ \\
\hline CAT score & $9.7 \pm 6.5$ & $10.0 \pm 4.5$ & $6.8 \pm 4.4$ & $-0.3(-6.8,6.4)$ & $2.7(-3.8,9.7)$ & $3.0(-4.5,10)$ \\
\hline mMRC (score/\%) & & & & $\mathrm{P}(\mathrm{Y} \mid \mathrm{FB})$ & $\mathrm{P}(\mathrm{Y} \mid \mathrm{ONB})$ & $\mathrm{P}(\mathrm{Y} \mid \mathrm{CG})$ \\
\hline 0 & $0(0 \%)$ & $0(0 \%)$ & $0(0 \%)$ & $0.0(0.0-0.0)$ & $0.0(0.0-0.0)$ & $0.0(0.0-0.0)$ \\
\hline 1 & $0(0 \%)$ & $0(0 \%)$ & $0(0 \%)$ & $0.0(0.0-0.1)$ & $0.0(0.0-0.2)$ & $0.0(0.0-0.2)$ \\
\hline 2 & $6(85 \%)$ & $5(100 \%)$ & $4(100 \%)$ & $0.9(0.6-1)^{\$}$ & $0.9(0.7-1)^{\$}$ & $0.9(0.7-1)^{\$}$ \\
\hline 3 & $1(15 \%)$ & $0(0 \%)$ & $0(0 \%)$ & $0.1(0.0-0.4)$ & $0.0(0.0-0.2)$ & $0.0(0.0-0.3)$ \\
\hline
\end{tabular}

BMI: body mass index; CAT: COPD Assessment Test (range of zero to 40); DLCO: diffusing capacity of the lung for carbon monoxide; RV/TLC: residual volume/total lung capacity; FEV1, forced expiratory volume in the first second; FVC, forced vital capacity; PI max , maximal inspiratory pressure; $6 \mathrm{MWT}, 6$ min walking test; mMRC: modified Medical Research Council dyspnea scale. CG: control group, FB: Feelbreathe group. ONB: oronasal breathe group. FB vs. ONB/FB vs. CG/ONB vs. CG: mean difference and $95 \%$ credible interval between groups. $\mathrm{P}(\mathrm{Y} \mid \mathrm{FB}) / \mathrm{P}(\mathrm{Y} \mid \mathrm{ONB}) / \mathrm{P}(\mathrm{Y} \mid \mathrm{CG})$ : probability of answer the score $\mathrm{Y}$ (i.e., $0,1,2,3)$, given a participant was assigned to a group at baseline. $\$ 95 \%$ credible interval does not include 0 for continuous variables or 0.5 for categorical variables. 

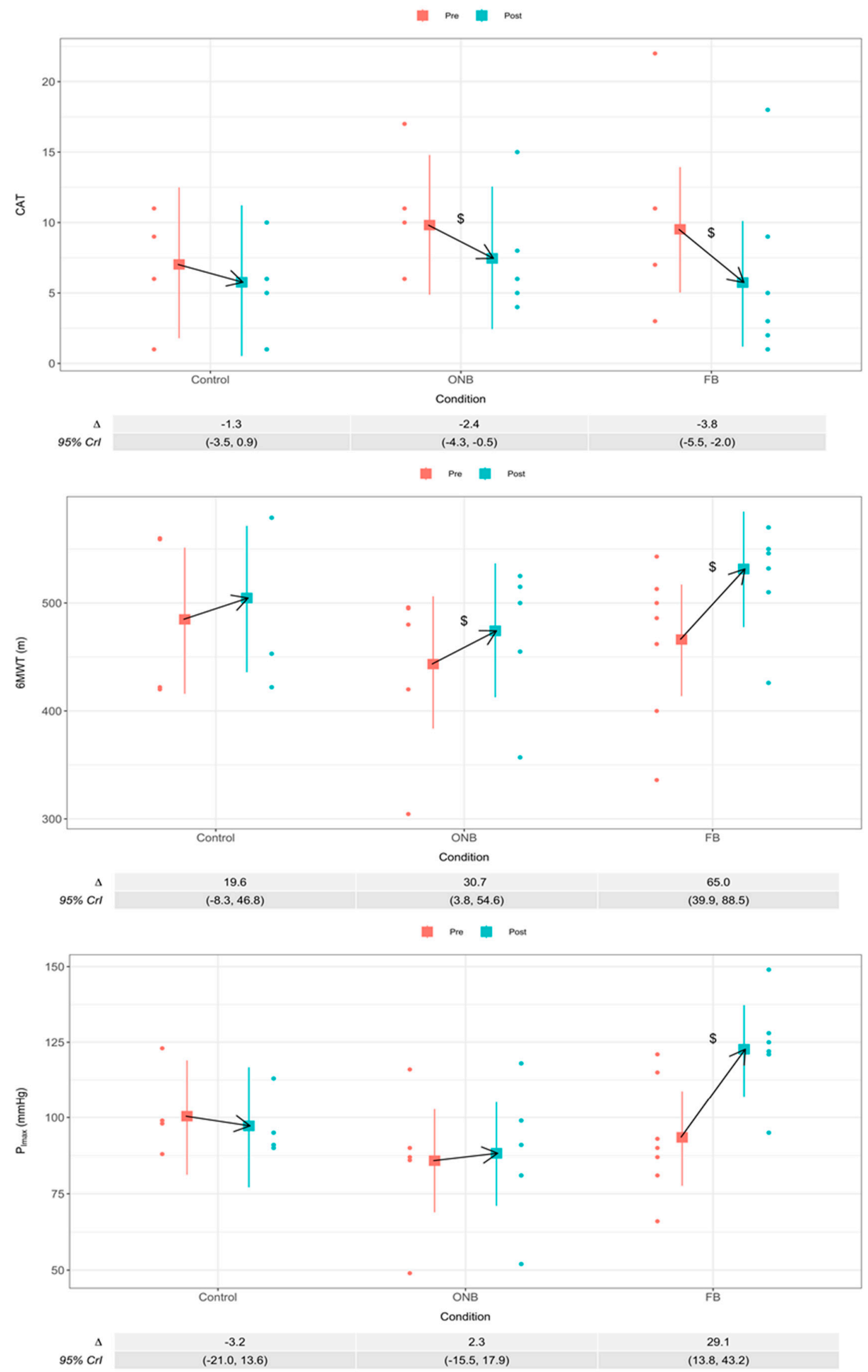

Figure 3. Mean difference $(\Delta)$ with $95 \%$ credible intervals ( $95 \% \mathrm{CrI}$ ) from pre to post-training in the CAT, 6MWT and $\mathrm{P}_{\text {Imax }} . \$ 95 \%$ CrI does not include 0 for the difference between pre- and post-training. 

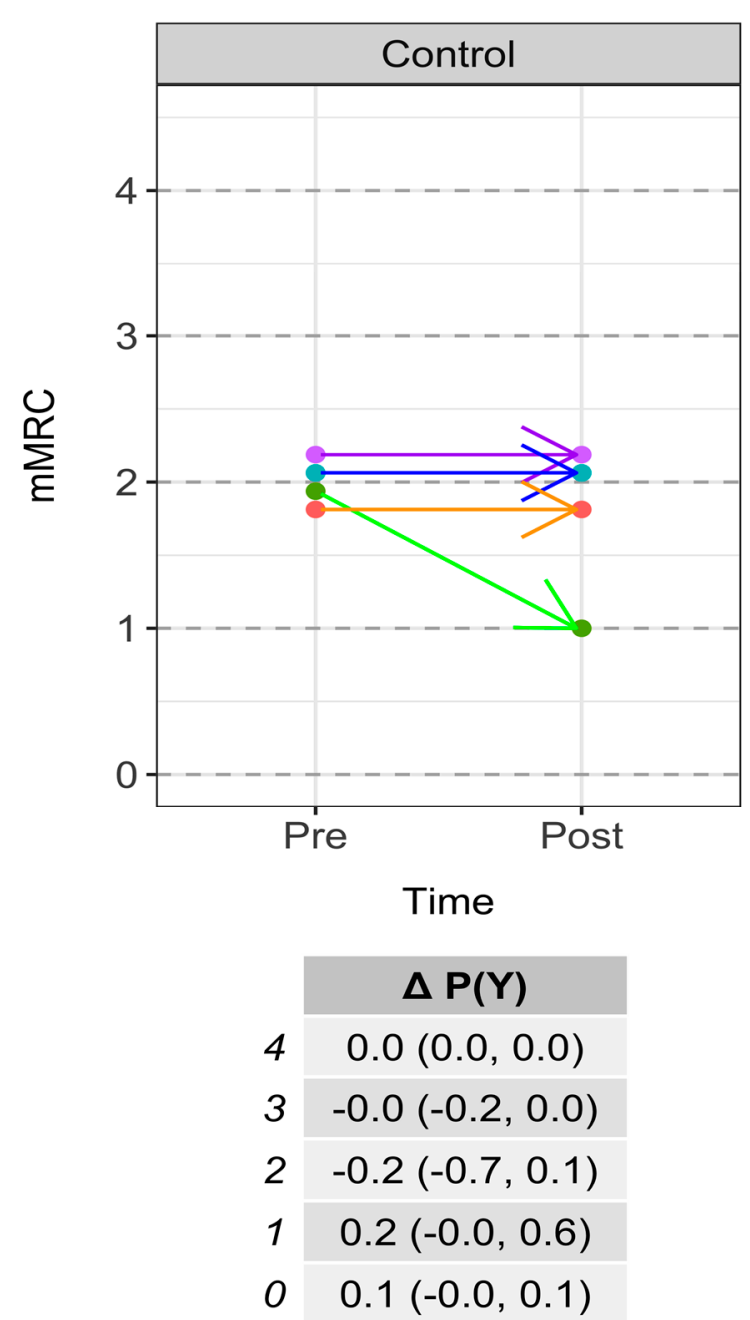

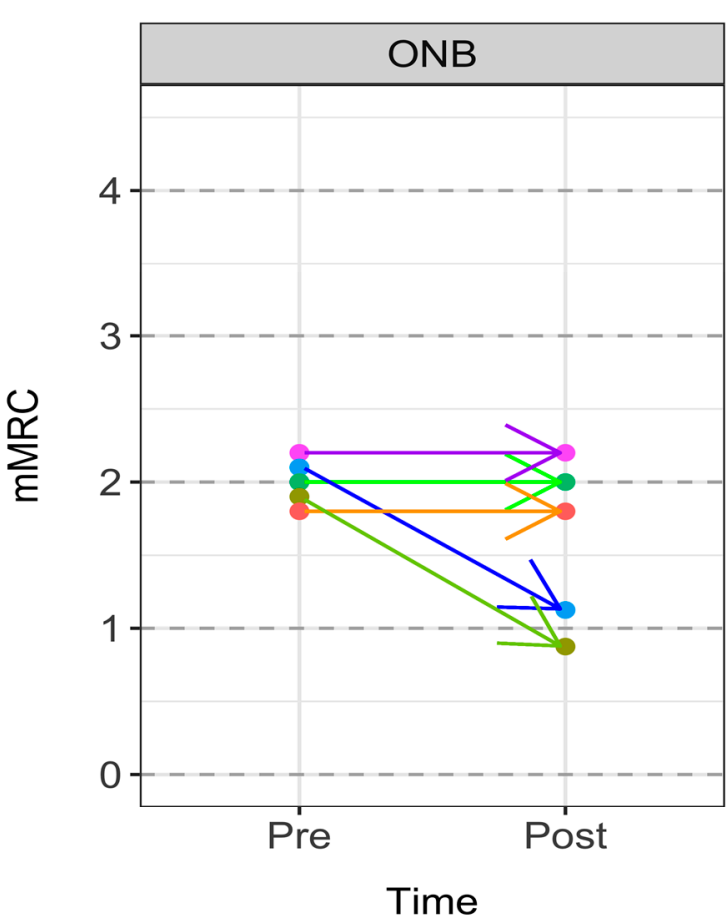

\section{$\Delta \mathbf{P}(\mathbf{Y})$}

$40.0(0.0,0.0)$

$3-0.0(-0.1,0.0)$

$2-0.3(-0.7,0.0)$

$10.3(0.0,0.7)$

$0 \quad 0.0(-0.0,0.1)$

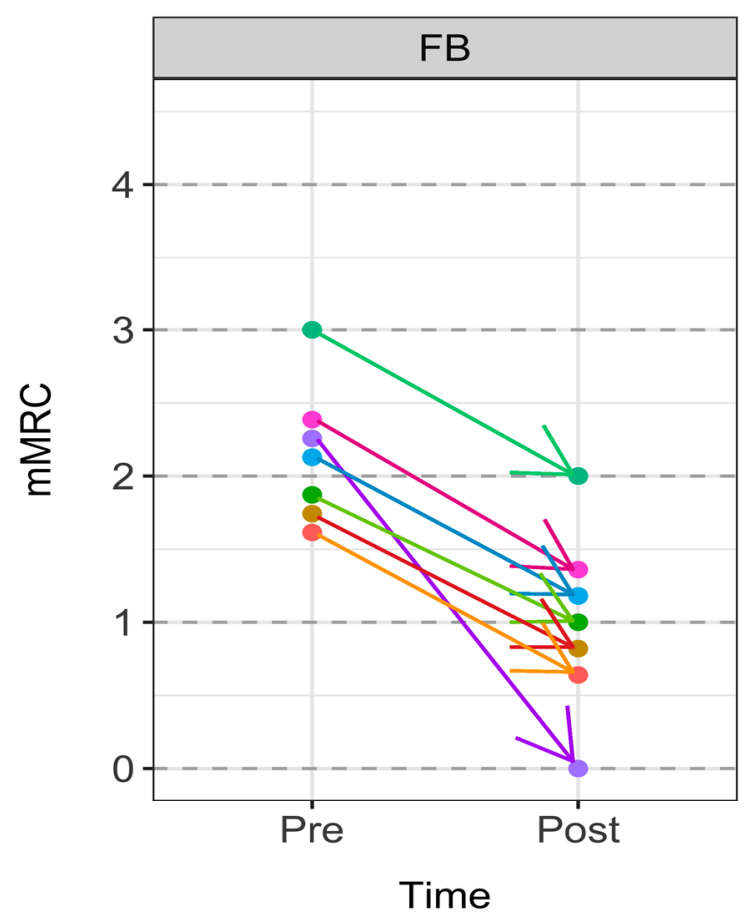

\section{$\Delta \mathrm{P}(\mathrm{Y})$}

$4-0.1(-0.1,0.0)$

$3-0.1(-0.3,-0.0)$

$2-0.7(-1,-0.4)$

$1 \quad 0.7(0.4,1)$

$0 \quad 0.1(0.0,0.4)$

Figure 4. Individual changes and difference $(\Delta)$ on the probability $(\mathrm{P})$ of response the row $\mathrm{Y}$ (i.e., $0,1,2,3$ or 4 ) from pre to post-training in the modified Medical Research Council dyspnea scale (mMRC). 
In the FB and ONB groups, the quality of life measure by CAT questionnaire improves, with the improvement greater in the FB group compared to the ONB group ( -3.8 vs. -2.4 , respectively) (Figure 3). In both groups, the CAT score decreases more than 2 points achieving the MCID [30]. In the $\mathrm{CG}$, there were no significant changes in CAT score (Figure 3).

$\mathrm{P}_{\text {Imax }}$ improved significantly in the FB group, without significant changes in the ONB and CG (Figure 3).

Table 2 shows differences comparing the three groups after and before pulmonary RP. The FB group achieves a significant increase in the $\mathrm{P}_{\text {Imax }}$ compared to the ONB group, and in the $\mathrm{P}_{\text {Imax }}$ and 6MWT compare to the CG.

Table 2. Between-differences for breathing conditions after and before pulmonary rehabilitation.

\begin{tabular}{cccc}
\hline Variables & FB vs. ONB & FB vs. CG & ONB vs. CG \\
\hline CAT & $-1.4(-3.8-1.3)$ & $-2.5(-5.2-0.5)$ & $-1.1(-3.7-2.0)$ \\
6MWT $(\mathrm{m})$ & $34.2(-0.2-70.7)$ & $45.4(10.3-81.6)^{\$}$ & $11.2(-23.1-49.0)$ \\
$\mathrm{P}_{\text {Imax }}(\mathrm{mmHg})$ & $26.8(3.7-49.4)^{\$}$ & $32.3(10.5-55.4)^{\$}$ & $5.5(-17.5-29.2)$ \\
\hline
\end{tabular}

FB: Feelbreathe group. ONB: oronasal breathe group. CG: control group. CAT: COPD Assessment Test; 6MWT, 6 min walking test; $\mathrm{PI}_{\max }$, maximal inspiratory pressure. $\$ 95 \%$ credible interval does not include 0 .

\section{Discussion}

In this prospective randomized trial, the Feelbreathe ${ }^{\circledR}$ device added on a supervised pulmonary $\mathrm{RP}$ in stable COPD patients provides greater improvements in quality of life, dyspnea, exercise capacity and inspiratory muscle strength compared to patients that did not use the FB device.

The 6MWT has been used to assess the efficacy of pulmonary RP, and the vast majority of these studies have shown an improvement in the distance walked in 6 min [31]. Due to sometimes having statistical significant differences that may not reflect a clinically relevant change, Jaeschke et al. defined the term minimal clinically important difference (MCID) as "the smallest difference in score in the domain of interest which patients perceive as beneficial" [32]. For pulmonary RP, an improvement in at least $30 \mathrm{~m}$ in the 6MWT is considered as MCID [29,33] and in this study, the FB and ONB groups achieved MCID, but the improvements were greater, more than double, in the FB group.

The concept of MCID can be applied to the CAT questionnaire. In this case, a change of at least 2 points in the score of the CAT is considered as MCID [30]. In this study, the FB and ONB groups achieved the MCID. The decrease in the CAT score was higher in the FB group, which may reflect the effect of the better exercise capacity of the patients [34], however, the difference between both groups did not achieve the MCID.

Only the FB group showed a significant decrease in the mMRC dyspnea score. Other studies have described improvements in dyspnea after a RP with exercise training in COPD patients, but usually with programs with high intensity $(70 \%-80 \%$ maximum workload) $[35,36]$, but in this study, the intensity of the exercise training was close to $60 \%$, ranging from 40 to $75 \%$.

Finally, only the FB group increased significantly the $P_{\operatorname{Imax}}$. This may be due to the FB device being able to provide a greater effect on inspiratory muscles, because it trains the inspiratory muscles while performing the whole rehabilitation session, unlike the others devices currently available for IMT that only can be used in static situation [17].

Lötters F et al., in a meta-analysis comparing IMT alone and IMT as adjunct to general RP in patients with COPD, demonstrated a significant increase in the inspiratory muscle strength and endurance in both groups, especially in patients with inspiratory muscle weakness $\left(\mathrm{P}_{\text {Imax }}<60 \mathrm{~cm}\right.$ $\mathrm{H}_{2} \mathrm{O}$ ) [10]. In those studies, when the patients have a ventilatory limitation during exercise, the addition of IMT to a RP increased the exercise capacity. This finding has been described by other authors $[37,38]$.

Magadle et al. assessed the influence of adding IMT to patients with COPD after finishing a 12 week RP [39]. IMT group showed a significant increase in $\mathrm{P}_{\operatorname{Imax}}$ and quality of life and decrease in the Borg scale dyspnea score, remaining unchanged the 6MWT, unlike our study in which FB and 
ONG groups improved the 6MWT distance. They argued that the absence of an additive influence of IMT to a pulmonary RP could be because the patients had achieved their full potential in response to pulmonary RP alone. In our study, the FB and the ONB groups performed a complete pulmonary RP that is highly effective for patients with COPD and further improvements in exercise capacity adding on other interventions may be challenging to obtain, but this is an excellent way to better discriminate the effect of the IMT in both groups.

Beaumont et al. [40] compared two PR programs, one with IMT versus no IMT in 32 COPD patients without inspiratory muscle weakness $\left(\mathrm{P}_{\operatorname{Imax}}>60 \mathrm{~cm} \mathrm{H}_{2} \mathrm{O}\right)$ as in our study, to demonstrate the effectiveness of IMT on dyspnea, $\mathrm{P}_{\text {Imax }}$ and 6MWT. The RP was very similar to ours, but the duration was only three weeks. They found a trend toward an improvement in dyspnea that was statistically significant in patients with $\mathrm{FEV}_{1}$ less than $50 \%$, but no changes were observed in $6 \mathrm{MWT}$ and $\mathrm{P}_{\text {Imax }}$.

Finally, in a recent systematic review, Camillo et al. [41] analyzed the effectiveness of therapies added on to conventional exercise training to maximize exercise capacity in patients with COPD. When IMT was used as add-on therapy to the RP, there was an improvement in the 6MWT distance in favor to the experimental group (12.72 $\mathrm{m}(95 \% \mathrm{CI}-16.81-42.26))$, but this increase was discrete and below the MCID.

The most important difference between the studies analyzed and our study is the use of a new inspiratory restriction device (Feelbreathe ${ }^{\circledR}$ ), that allows an IMT during all the period that the patient is receiving the pulmonary $\mathrm{RP}$, so the action of the intervention on inspiratory muscles is continuous and probably of greater intensity. This device allows for a simultaneous training of the respiratory and skeletal muscles when the patients are receiving the rehabilitation. The IMT performed in the rest of the studies is in static situations and the action of the IMT is for a limited period of time during the whole pulmonary RP.

In our study, the baseline inspiratory muscle pressure was over $60 \mathrm{mmHg}$ in all groups, nonetheless, the FB group showed improvements in the final $\mathrm{P}_{\text {Imax }}$, and this may be due to the same reason, a higher intensity in the IMT developed by the FB device.

A limitation of our study was the sample size and the high number of drop off leading to small size unbalance pulmonary rehabilitation groups. To address this problem, we analyzed our data relying on the principles of Bayesian hierarchical modeling (i.e., quantify the uncertainty around a quantity based on the data we have at hand using prior information about that quantity). Moreover, the hierarchical part of the modeling (also known as multilevel modeling) allowed us to obtain a reliable estimate of the parameters by partial pooling.

Another limitation of our study is that the design was prospective randomized but open, because it was impossible to perform a double-blind design due to the characteristics of the device.

As one of the advantages of the FB device is that it is easy to use and the possibility of being used safely in dynamic situations, so it could be beneficial for training the inspiratory muscles in ambulatory patients with COPD, for example, while they are walking or during their daily activities or to maintain the long-term effects of a supervised pulmonary RP.

\section{Conclusions}

In conclusion, the Feelbreathe ${ }^{\circledR}$ device can be useful as an add-on therapy to a supervised pulmonary rehabilitation program for patients with COPD, improving dyspnea, quality of life, exercise tolerance and inspiratory muscle strength. According to these results, in the future, it could be interesting to study if the Feelbreathe ${ }^{\circledR}$ device could be useful for unsupervised exercise training or for daily activities in patients with COPD. 
Author Contributions: All authors played a role in the content and writing of the manuscript. A.A. and J.L.G.-M. were the principal investigators and contributed the original idea for the study. J.L.G.-M., A.A., J.G.P.-G., M.C.-G. had input into the study design and conduct of study; C.E.-D. and A.A. contributed to subject recruitment. C.E.-D., J.L.G.-M., C.V.-P. and A.A. collected the data; J.R.F.-S. performed data analysis; J.L.G.-M., J.R.F.-S., C.V.-P., A.A., M.C.-G. and J.G.P.-G. interpretation of the data and writing of the manuscript. Each one of the authors has read and becomes responsible for any of the aspects included in the manuscript. All authors have read and agreed to the published version of the manuscript.

Funding: This research was funded by Sociedad Española de Neumología y Cirugía Torácica (SEPAR). Grant number: 099/2015.

Acknowledgments: Special thanks are due to the University Hospital Puerta del Mar, Cádiz (Spain) and to the Center for Sports Medicine, (Cádiz, Spain) for the help and collaboration received.

Conflicts of Interest: The authors declare no conflict of interest.

\section{References}

1. Miravitlles, M.; Soler-Cataluña, J.J.; Calle, M.; Molina, J.; Almagro, P.; Quintano, J.A.; Trigueros, J.A.; Cosío, B.G.; Casanova, C.; Antonio Riesco, J.; et al. Guía española de la enfermedad pulmonar obstructiva crónica (GesEPOC) 2017. Tratamiento farmacológico en fase estable. Arch. Bronconeumol. 2017, 53, 324-335. [CrossRef] [PubMed]

2. Singh, D.; Agusti, A.; Anzueto, A.; Barnes, P.J.; Bourbeau, J.; Celli, B.R.; Criner, G.J.; Frith, P.; Halpin, D.M.G.; Han, M.; et al. Global strategy for the diagnosis, management, and prevention of Chronic obstructive pulmonary disease. Eur. Respir. J. 2019, 53, 1900164. [CrossRef] [PubMed]

3. Celli, B.R.; MacNee, W.; Agusti, A.; Anzueto, A.; Berg, B.; Buist, A.S.; Calverley, P.M.A.; Chavannes, N.; Dillard, T.; Fahy, B.; et al. Standards for the diagnosis and treatment of patients with COPD: A summary of the ATS/ERS position paper. Eur. Respir. J. 2004, 23, 932-946. [CrossRef] [PubMed]

4. Spruit, M.A.; Singh, S.J.; Garvey, C.; Zu Wallack, R.; Nici, L.; Rochester, C.; Hill, K.; Holland, A.E.; Lareau, S.C.; Man, W.D.C.; et al. An official American thoracic society/European respiratory society statement: Key concepts and advances in pulmonary rehabilitation. Am. J. Respir. Crit. Care Med. 2013, 188, e13-e64. [CrossRef] [PubMed]

5. Rochester, C.L.; Vogiatzis, I.; Holland, A.E.; Lareau, S.C.; Marciniuk, D.D.; Puhan, M.A.; Spruit, M.A.; Masefield, S.; Casaburi, R.; Clini, E.M.; et al. An official American Thoracic Society/European Respiratory Society policy statement: Enhancing implementation, use, and delivery of pulmonary rehabilitation. Am. J. Respir. Crit. Care Med. 2015, 192, 1373-1386. [CrossRef] [PubMed]

6. Orozco-Levi, M.; Gea Guiral, J. Cambios musculares en la enfermedad pulmonar obstructiva crónica: La teoría de los compartimientos. Arch. Bronconeumol. 2000, 36, 95-102. [CrossRef]

7. Lacasse, Y.; Guyatt, G.H.; Goldstein, R.S. The components of a respiratory rehabilitation program: A systematic overview. Chest 1997, 111, 1077-1088. [CrossRef]

8. Pothirat, C.; Limsukon, A.; Chaiwong, W.; Phetsuk, N.; Liwsrisakun, C.; Bumroongkit, C.; Deesomchok, A.; Theerakittikul, T. Long-term efficacy of intensive cycle ergometer exercise training program for advanced COPD patients. Int. J. Chron. Obstruct. Pulmon. Dis. 2015, 10, 133. [CrossRef]

9. Gosselink, R.; De Vos, J.; Van Den Heuvel, S.P.; Segers, J.; Decramer, M.; Kwakkel, G. Impact of inspiratory muscle training in patients with COPD: What is the evidence? Eur. Respir. J. 2011, 37, 416-425. [CrossRef]

10. Lötters, F.; van Tol, B.; Kwakkel, G.; Gosselink, R. Effects of controlled inspiratory muscle training in patients with COPD: A meta-analysis. Eur. Respir. J. 2002, 20, 570-576. [CrossRef]

11. Beaumont, M.; Forget, P.; Couturaud, F.; Reychler, G. Effects of inspiratory muscle training in COPD patients: A systematic review and meta-analysis. Clin. Respir. J. 2018, 12, 2178-2188. [CrossRef] [PubMed]

12. González-Montesinos, J.L.; Vaz Pardal, C.; Fernández Santos, J.R.; Arnedillo Muñoz, A.; Costa Sepúlveda, J.L.; Gómez Espinosa de los Monteros, R. Efectos del entrenamiento de la musculatura respiratoria sobre el rendimiento. Revisión bibliográfica. Rev. Andal. Med. Deport. 2012, 5, 163-170. [CrossRef]

13. González Montesinos, J.L.; Fernández Santos, J.; Vaz Pardal, C.; Arnedillo Muñoz, A. Dispositivo para el Entrenamiento de la Musculatura nasal. Oficina Española de Patentes y Marcas U201930922, 3 June 2019.

14. Morton, A.R.; King, K.; Papalia, S.; Goodman, C.; Turley, K.R.; Wilmore, J.H. Comparison of maximal oxygen consumption with oral and nasal breathing. Aust. J. Sci. Med. Sport 1995, 27, 51-55. 
15. Bailey, S.J.; Romer, L.M.; Kelly, J.; Wilkerson, D.P.; DiMenna, F.J.; Jones, A.M. Inspiratory muscle training enhances pulmonary $\mathrm{O}(2)$ uptake kinetics and high-intensity exercise tolerance in humans. J. Appl. Physiol. 2010, 109, 457-468. [CrossRef] [PubMed]

16. Illi, S.K.; Held, U.; Frank, I.; Spengler, C.M. Effect of respiratory muscle training on exercise performance in healthy individuals: A systematic review and meta-analysis. Sport. Med. 2012, 42, 707-724. [CrossRef] [PubMed]

17. González-Montesinos, J.L.; Ponce-González, J.G.; Vicente-Campos, D.; López-Chicharro, J.; Fernández-Santos, J.R.; Vaz-Pardal, C.; Costa-Sepúlveda, J.L.; Conde-Caveda, J.; Castro-Piñero, J. Efectos de un dispositivo de restricción ventilatoria nasal sobre la ventilación pulmonar e intercambio gaseoso durante el ejercicio en personas sanas. Nutr. Hosp. 2016, 33. [CrossRef]

18. Vogelmeier, C.F.; Criner, G.J.; Martinez, F.J.; Anzueto, A.; Barnes, P.J.; Bourbeau, J.; Celli, B.R.; Chen, R.; Decramer, M.; Fabbri, L.M.; et al. Global Strategy for the Diagnosis, Management, and Prevention of Chronic Obstructive Lung Disease 2017 Report. GOLD Executive Summary. Am. J. Respir. Crit. Care Med. 2017, 195, 557-582. [CrossRef]

19. Cotes, J.E.; Chinn, D.J. MRC questionnaire (MRCQ) on respiratory symptoms. Occup. Med. 2007, 57, 388. [CrossRef]

20. Jones, P.W.; Harding, G.; Berry, P.; Wiklund, I.; Chen, W.-H.; Kline Leidy, N. Development and first validation of the COPD Assessment Test. Eur. Respir. J. 2009, 34, 648-654. [CrossRef]

21. Culver, B.H.; Graham, B.L.; Coates, A.L.; Wanger, J.; Berry, C.E.; Clarke, P.K.; Hallstrand, T.S.; Hankinson, J.L.; Kaminsky, D.A.; MacIntyre, N.R.; et al. Recommendations for a Standardized Pulmonary Function Report. An Official American Thoracic Society Technical Statement. Am. J. Respir. Crit. Care Med. 2017, 196, 1463-1472. [CrossRef]

22. Redlich, C.A.; Tarlo, S.M.; Hankinson, J.L.; Townsend, M.C.; Eschenbacher, W.L.; Von Essen, S.G.; Sigsgaard, T.; Weissman, D.N.; American Thoracic Society Committee on Spirometry in the Occupational Setting Official. American Thoracic Society technical standards: Spirometry in the occupational setting. Am. J. Respir. Crit. Care Med. 2014, 189, 983-993. [CrossRef] [PubMed]

23. ATS Committee on Proficiency Standards for Clinical Pulmonary Function Laboratories ATS statement: Guidelines for the six-minute walk test. Am. J. Respir. Crit. Care Med. 2002, 166, 111-117. [CrossRef] [PubMed]

24. Foster, C.; Florhaug, J.A.; Franklin, J.; Gottschall, L.; Hrovatin, L.A.; Parker, S.; Doleshal, P.; Dodge, C. A New Approach to Monitoring Exercise Training. J. Strength Cond. Res. 2001, 15, 109-115. [PubMed]

25. Van de Schoot, R.; Broere, J.J.; Perryck, K.H.; Zondervan-Zwijnenburg, M.; Van Loey, N.E. Analyzing small data sets using Bayesian estimation: The case of posttraumatic stress symptoms following mechanical ventilation in burn survivors. Eur. J. Psychotraumatol. 2015, 6, 25216. [CrossRef]

26. Van de Schoot, R.; Sijbrandij, M.; Depaoli, S.; Winter, S.D.; Olff, M.; van Loey, N.E. Bayesian PTSD-trajectory analysis with informed priors based on a systematic literature search and expert elicitation. Multivariate Behav. Res. 2018, 53, 267-291. [CrossRef]

27. Gelman, A.; Simpson, D.; Betancourt, M. The prior can often only be understood in the context of the likelihood. Entropy 2017, 19, 555. [CrossRef]

28. Bürkner, P.-C. brms: An R package for Bayesian multilevel models using stan. J. Stat. Softw. 2017, 80, 21555. [CrossRef]

29. Holland, A.E.; Spruit, M.A.; Troosters, T.; Puhan, M.A.; Saey, D.; Mccormack, M.C.; Carlin, B.W.; Sciurba, F.C.; Pitta, F.; Wanger, J.; et al. An official European Respiratory Society/American Thoracic Society technical standard: Field walking tests in chronic respiratory disease. Eur. Respir. J. 2014, 44, 1428-1446. [CrossRef]

30. Kon, S.S.C.; Canavan, J.L.; Jones, S.E.; Nolan, C.M.; Clark, A.L.; Dickson, M.J.; Haselden, B.M.; Polkey, M.I.; Man, W.D.C. Minimum clinically important difference for the COPD Assessment Test: A prospective analysis. Lancet Respir. Med. 2014, 2, 195-203. [CrossRef]

31. Xi, F.; Wang, Z.; Qi, Y.; Brightwell, R.; Roberts, P.; Stewart, A.; Sim, M.; Wang, W. Long-term effect of respiratory training for chronic obstructive pulmonary disease patients at an outpatient clinic: A randomised controlled trial. Clin. Transl. Med. 2015, 4, 31. [CrossRef]

32. Jaeschke, R.; Singer, J.; Guyatt, G.H. Measurement of health status. Ascertaining the minimal clinically important difference. Control. Clin. Trials 1989, 10, 407-415. [CrossRef] 
33. Puhan, M.A.; Chandra, D.; Mosenifar, Z.; Ries, A.; Make, B.; Hansel, N.N.; Wise, R.A.; Sciurba, F. The minimal important difference of exercise tests in severe COPD. Eur. Respir. J. 2011, 37, 784-790. [CrossRef] [PubMed]

34. Dodd, J.W.; Hogg, L.; Nolan, J.; Jefford, H.; Grant, A.; Lord, V.M.; Falzon, C.; Garrod, R.; Lee, C.; Polkey, M.I.; et al. The COPD assessment test (CAT): Response to pulmonary rehabilitation. A multicentre, prospective study. Thorax 2011, 66, 425-429. [CrossRef] [PubMed]

35. Osterling, K.; MacFadyen, K.; Gilbert, R.; Dechman, G. The effects of high intensity exercise during pulmonary rehabilitation on ventilatory parameters in people with moderate to severe stable COPD: A systematic review. Int. J. Chron. Obstruct. Pulmon. Dis. 2014, 9, 1069-1079. [CrossRef] [PubMed]

36. Wadell, K.; Webb, K.A.; Preston, M.E.; Amornputtisathaporn, N.; Samis, L.; Patelli, J.; Guenette, J.A.; O'Donnell, D.E. Impact of Pulmonary Rehabilitation on the Major Dimensions of Dyspnea in COPD. COPD J. Chronic Obstr. Pulm. Dis. 2013, 10, 425-435. [CrossRef]

37. Scherer, T.A.; Spengler, C.M.; Owassapian, D.; Imhof, E.; Boutellier, U. Respiratory muscle endurance training in chronic obstructive pulmonary disease: Impact on exercise capacity, dyspnea, and quality of life. Am. J. Respir. Crit. Care Med. 2000, 162, 1709-1714. [CrossRef]

38. Sonne, L.J.; Davis, J.A. Increased exercise performance in patients with severe COPD following inspiratory resistive training. Chest 1982, 81, 436-439. [CrossRef]

39. Magadle, R.; McConnell, A.K.; Beckerman, M.; Weiner, P. Inspiratory muscle training in pulmonary rehabilitation program in COPD patients. Respir. Med. 2007, 7, 1500-1505. [CrossRef]

40. Beaumont, M.; Mialon, P.; Ber-Moy, C.; Lochon, C.; Péran, L.; Pichon, R.; Gut-Gobert, C.; Leroyer, C.; Morelot-Panzini, C.; Couturaud, F. Inspiratory muscle training during pulmonary rehabilitation in chronic obstructive pulmonary disease. Chron. Respir. Dis. 2015, 12, 305-312. [CrossRef]

41. Camillo, C.A.; Osadnik, C.R.; van Remoortel, H.; Burtin, C.; Janssens, W.; Troosters, T. Effect of "add-on" interventions on exercise training in individuals with COPD: A systematic review. ERJ Open Res. 2016, 2, 00078-02015. [CrossRef]

(C) 2020 by the authors. Licensee MDPI, Basel, Switzerland. This article is an open access article distributed under the terms and conditions of the Creative Commons Attribution (CC BY) license (http://creativecommons.org/licenses/by/4.0/). 